\title{
Elementary curriculum about conflict resolution: Can children handle global politics?
}

\author{
Kathy Bickmore \\ OISE/ University of Toronto
}

In Theory and Research in Social Education 27:1 (Winter 1999), 45-69.

\begin{abstract}
Children can develop their capacities to handle both social and interpersonal conflict in elementary school, without sacrificing attention to academic achievement. This case study, based in one grade four and five classroom with a diverse population, shows how a curriculum focusing on the concept of conflict was tied tightly to social studies and other subject area learning goals, and woven around instances of global as well as interpersonal problems. Complex social or political material, which is frequently avoided in the elementary classroom, served to strengthen the curriculum's conceptual framework and to provide entry points for diverse students to comprehend the sources and management of conflict. The paper presents analysis of descriptive vignettes, selected to represent evidence of curriculum process and content and students' developing understandings of conflict.
\end{abstract}

Pluralist democracy depends on diverse citizens' development of capacity to think independently in the face of conflict. Conflict management, an important ingredient of democratic education, is increasingly taught (explicitly) in public schools. However, these lessons are often marginal to the core curriculum, and often conflict lessons emphasize interpersonal communication and impulse control instead of broader concept development. Complex or controversial and larger-scale human conflicts are often ignored, especially in elementary social studies (Hahn 1996, Houser 1996, Soley 1996) and in conflict resolution programs (Carruthers et. al. 1996, Johnson \& Johnson 1996, Noguera 1995). In this postmodern world — involving instant mass communications and diverse cultural identities - is it appropriate to assume that children are more capable of learning about inter-personal conflicts than inter-group conflicts (Elkind 1995)? Especially in multicultural classrooms, children may draw from a wide range of global as well as local knowledge to understand human problems. Conflict education should be broadened and brought in from the margins, as one key component of education for democratic citizenship.

This paper explores the ways diverse elementary students may come to understand and to constructively handle social and interpersonal conflict, in the context of an implemented social education curriculum unit in one public elementary classroom. In this classroom, conflict education was integrated with other academic subject-matter, especially language and social studies. The lessons were organized around key ideas for understanding conflict, based on conflict resolution theory (Curle \& Dugan 1982, Deutsch 1993, Kriesberg 1982), using both familiar and unfamiliar examples of conflict at various stages. The class studied situations such as the Hutu-Tutsi conflict in Rwanda and Zaire, bullying and exclusion conflicts on the school playground, conflicts over the appropriate development and use of water resources, and the ArabIsraeli conflict. Pedagogies brought in the children's diverse experiences through drama, examination of literature and geography, small group tasks, and open discussion. The young people in this classroom showed their interest in a broad range of conflicts, well beyond the skillbased interpersonal conflict resolution often offered in elementary schools. This exploratory study develops a conceptual framework for understanding and conducting conflict education, within a 
broader academic curriculum aimed at preparation for democratic citizenship in pluralistic contexts.

Following a review of related literature and a description of research methods, the paper presents a series of vignettes illustrating particular lessons and the student work they inspired. The analysis focuses on the processes and subject-matter through which students developed understandings about conflict and conflict resolution. The study substantiates the idea that young children are indeed able to handle complex political and international conflicts. In fact, their conceptual sophistication for handling interpersonal conflicts seems to be enhanced by their work making sense of these intergroup conflicts, in the context of social studies and across the curriculum. The case study demonstrates how potentially-controversial lessons regarding social diversity and conflict can enhance students' preparation for managing both interpersonal and social conflict.

\section{Conceptual framework:}

Conflict is a powerful organizing idea in social education: understanding the concept of conflict is useful for learning to manage interpersonal and social problems (Deutsch 1993, Kreidler 1990), and thus important for democratic citizenship participation (Bickmore 1997, Hahn 1996). Because conflict is a natural element of human life, it intersects with the key ideas and knowledge-building processes of any curricular subject, and especially the social studies (Bickmore 1999). Conflict education's major elements include:

(1) understanding the causes and forms of conflict (diverse human needs and wants, violence and nonviolence),

(2) understanding the role of conflict in human relationships, especially the notion of contrasting viewpoints, feelings, and interests,

(3) understanding how conflicts present choices, and capacity to evaluate the positive and negative consequences of such choices,

(4) capacity to apply conflict resolution processes, to create and evaluate multiple potential responses to problems.

It is possible and desirable to integrate these concepts into the academic curriculum. Conflict is a prime example of a thematic focus that connects school subjects to one another and to 'real' democratic life (Carruthers et. al. 1996). Curriculum integration builds in multiple applications of concepts, and extends developmental time, to improve students' capacities to generalize and to transfer school knowledge to new uses (Taba 1963). Authentic and democratically-oriented intellectual work in social education involves analysis of problems, interpretation of viewpoints, and negotiation of meanings, in ways that connect 'academic' questions to real experiences and social problems, that is to students' present and future roles as citizens (Scheurman \& Newmann 1998). Integration of conflict in the curriculum stimulates thinking and makes school knowledge more meaningful for young learners. Where curriculum avoids or censors conflicts or controversies, classrooms become apparently safe but complacent environments: these offer little opportunity to learn, to include marginalized students, or to develop interest in school or citizen action (Houser 1996, Mellor 1996).

The notion of 'expanding horizons' is alive and well in North American public school curricula. Conflict resolution lessons, like much else in the social studies, are still generally sequenced in a linear fashion - beginning young children with the small, local, familiar, and noncontroversial, and moving in later grades (if at all) into wider global or political arenas. The assumptions underlying this curriculum pattern are flawed. First, such curriculum assumes that people's minds develop in concentric circles, that young children are more interested in familiar neighbors than in the strange and peculiar (Egan 1986). Worse, it relies on an assumed cultural common ground that does not take into account students' diverse life experiences. It ignores the experiential knowledge of children brought up in contested regimes, or in rapidly-changing circumstances such as immigration or cultural border areas, which may be very useful for understanding inter-group conflicts (Anzaldúa 1987, Merelman 1990). 
The notion of 'developmental appropriateness,' upon which the expanding horizons approach is based, can be a cover for educators' own fears of handling potentially-controversial topics (Miner 1998, Soley 1996). Limiting elementary students' horizons of exploration risks rendering school knowledge irrelevant to the lived concerns of today's children. In conflict and social education, an overly-cautious expanding horizons approach misses the powerful motivation embedded in children's imaginations and in their media-fed awareness of the wider world.

\section{Research method and setting:}

This single case study investigates curriculum development regarding conflict education, and diverse students' responses to the learning opportunities thus created, in one social context. Following an adaptation of the grounded theory approach (Glaser \& Strauss 1967), I collected detailed descriptions of conflict education activities, including formative assessment tasks, in one multicultural elementary classroom. Data collection was interspersed with analysis, conducted independently and in frequent dialogue with the teacher. This resulted in refinement of conceptual categories and further elaboration - first, of the conflict education curriculum-in-use in this context, and second, of the more general understanding of social education for conflict resolution toward which this study is reaching.

Throughout the process, I was an engaged participant observer, drawing insights from my extended direct involvement with one teacher and her students. Evelyn Fox Keller calls this stance dynamic objectivity: it "aims at a form of knowledge that grants to the world around us its independent integrity but does so in a way that remains cognizant of, indeed relies on, our connectivity with that world" $(1985, \mathrm{p} .117)$. While sweeping conclusions would be unwarranted from such a small study, this kind of research deepens our understanding through direct engagement and collaborative dialogue in a particular context.

The site for this research was chosen purposively, as a setting that embodied many of the questions and possibilities embedded in the research effort. In this combined grade four and five class in an urban public school, well over half of the 33 students were recent immigrants, with diverse language abilities and cultural backgrounds. The class included $24(73 \%)$ in grade four, and $9(27 \%)$ in grade five who had been with the same teacher the previous year, heterogeneously grouped in terms of achievement. The class had 14 girls (42\%) and 19 boys (58\%). More than two thirds of the children were first or second generation immigrants, coming mostly from the Middle East, India, China, Somalia, Trinidad and Tobago, Greece, and the earlier European migrations to Canada. The teacher, Ms. Alison (a pseudonym), had considerable confidence, skill, and flexibility, rooted in 24 years of teaching and educational leadership. Conflict resolution was one of a small number of cross-curricular "theme" units offered that year, which emphasized social studies, arts, and language arts.

I was regularly involved in the life of Ms. Alison's classroom during the life of the conflict resolution theme unit, from October to March (1996-97) and for a few days in June (1997). I observed more than 30 hours of classroom lessons, including approximately 18 hours that I co-led or assisted with Ms. Alison. Outside of class time, I met with Ms. Alison for 12 hours of analysis, discussion, and joint planning. Ms. Alison taught essentially the same group of students the following year in grades five and six; we held a follow-up discussion a year after the study (March 1998). In addition, I was regularly involved in this school as a whole throughout the school year, in relation to other conflict resolution and teacher education responsibilities. (Pseudonyms are used, details about individual children have been masked, and formal assessments [grades] were not recorded in research notes.)

The main research question asks what conflict education would look like, if it included global and well as interpersonal topics, integrated into an upper-elementary curriculum (in an urban classroom with a diverse multicultural population). Two related questions elaborate the particular concerns of this study:

- How could conflict education be woven together with academic achievement? That is, how could children develop their capacities to handle the concept of conflict, while at the same 
time pursuing core curricular objectives, especially in language and social studies?

-What might constitute an alternative to the expanding horizons approach to conflict studies?

Would complex social or political material present a more difficult developmental challenge

to young learners than interpersonal topics?

These questions are addressed through analysis of descriptive vignettes (taken from field notes and identified by indented text below) regarding the classroom's curriculum-in-use, selected to represent evidence of curriculum process and content, and students' developing understandings of conflict.

\section{Findings:}

The following vignettes were chosen to reflect the three major themes in understanding conflict that emerged in Ms. Alison's curriculum - (1) What is conflict? (2) Sources of conflict: How do conflicts reflect different human needs and perspectives? (3) Managing conflict: What are the consequences of different choices in handling conflict? Each of these themes builds upon the preceding theme, gradually elaborating the children's understandings of the concept.

Report cards sent home to students' parents in early February emphasized "Conflicts in school, Ontario, and the world" as the major cross-curricular focus of the first semester. Ms. Alison's assessments emphasized social studies, language arts, drama, and fine arts outcomes. In relation to the first theme, understanding conflict, curriculum expectations (from the school board's version of the Ontario Common Curriculum) included:

- listen for information to understand others' experience;

- speak with growing confidence to inform, question, and understand others' experience in a variety of school situations;

- explain the relationships between present actions and preferred and probable futures;

- investigate fictional and real relationships, feelings, and experiences through role play and presentation;

- use appropriate language to [identify and] resolve conflicts;

- express personal views through art work;

- demonstrate an understanding and appreciation of diverse people through the direct experience of drama and music.

In relation to the second theme, human needs and perspectives as sources of conflict, curriculum expectations included:

- recognize that an event can have more than one cause;

- identify sources of conflict in the school, community, and society and suggest

appropriate ways to deal with them;

- read fiction, news articles, and other informative materials ... that reflect diversity of

Canadian and global society;

- analyze how media influences our perceptions about other people;

- use inclusive and bias free language and explain its importance;

- describe a variety of perspectives on an issue, and explain how perspectives are shaped

and how they are changed with new information;

- write in role;

- locate significant places in Canada and in world events;

- identify situations in Canada and the world where resources are distributed unequally.

In the second semester, Ms. Alison extended the concept of conflict to include math and science in addition to arts, language arts, and social studies. In particular, the class studied bullying on the playground, and human interaction with the water cycle, locally and in relation to an area study of the Middle East (water was also another theme unit treated separately). In 
relation to the third theme, managing conflict, additional curriculum expectations included:

- describe cyclical occurrences and changes in the natural world which affect every day life;

- apply mathematical concepts to new situations and other subject areas [e.g. creating pie charts and graphs depicting uses of water];

- examine different explanations of and solutions to a problem, determine their validity, and apply the most appropriate solution;

- discuss how ... technological developments are human endeavors and are influenced by all the factors which affect individuals and society;

- make informed reasoned judgments about what is fair in particular cases.

The social scientific concept of conflict thus provides a connection among knowledge and skill development opportunities in several different curriculum areas. The vignettes proceed chronologically, reflecting the conceptual organization of this curriculum, and are interspersed with commentary to show how data were analyzed. Other lessons are summarized briefly, to give a sense of where the vignettes fit in the whole curriculum strand. The final vignette revisits the first theme, to show the students' development of understanding over the eight months of the study.

\section{What is conflict?}

The research began on October 21 (and ended in June) by asking students to define conflict, by generating examples of conflict and contrasting these with non-examples. The children gathered in a circle. Ms. Alison introduced me to the students, saying that I would be joining the class for some new activities. I told the group that I was interested in how young people (such as themselves) learn to handle conflict, problems, and peacemaking. Ms. Alison asked the class to, "Think of a word I already know," that would describe all the following examples.

"Just now [as the class gathered on the carpet], somebody said "the boys always get the cushions.' That's an example. Today, our class and another class arrived at the library at the same time [while there was room for only one class].... Earlier, we talked about the General Motors strike.... Dr. Bickmore said 'problem' a moment ago; that's a hint. What do we call problems or disagreements? What's a synonym?" Nine or ten students made guesses, most of them not even close. Ms. Alison started spelling out the word CONFLICT on the chalkboard; she got all the way past L before anybody guessed the word. Ms. Alison wrote the word CONFLICT, pronounced it aloud, and asked, "How many know that word?" Eleven (of 33) students raised their hands. Ms. Alison asked them to give an example: five or six successfully gave examples of conflicts.

This initial unfamiliarity with the term "conflict" is less surprising when one recalls that English was a second language for almost two thirds of the class. Language proficiency ranged from basic oral functioning (and almost no literacy) to well above grade level in fluency and vocabulary, among both monolingual English and ESL speakers. From the blank looks on their faces and the unevenness of their explanations and examples, however, it is clear that the difficulty was not merely vocabulary. The concept of conflict was initially unfamiliar to most of the students. However, the experience of conflict was familiar, and in the passage below one can see that some of the students were beginning to connect their experiences with the concept. The concept-building process continued for about an hour that day, with students presenting many examples and thinking aloud about why each one might be (or might not be) an instance of conflict.

I prompted for personal and interpersonal conflicts, asking students to recall and 
imagine decisions they made, or problems they encountered, at various stages of the day ("When you got ready for school this morning ... Conflicts that have happened here at school ... Problems you have had after school...'). Gradually, the children's examples became more frequently correct applications of the term conflict, such as: whether to wear a jacket, not wanting to get out of bed but not wanting to be late to school, disagreement with mother regarding what to eat for breakfast, problems with pushing or sharing toys at recess, arguments with siblings. With some direct encouragement of a few quiet students, eventually every child offered an example of a conflict in which they had been a participant.

Later that afternoon, I asked the class for examples of conflict in books they had read, to see whether they had begun to understand that conflicts could take other forms beyond the intrapersonal or interpersonal. This question didn't provoke much response. When Ms. Alison reminded the class of the Little House on the Prairie book they had read together recently (Wilder), one confident child answered that there was a conflict between the Indians and the Pioneers over control of the land where the story's main characters settled. To end the lesson, Ms. Alison asked the class to synthesize: "What do all these conflicts have in common?" Three or four students offered the following characteristics: people wanting different things, (sometimes) anger, a problem having two or more sides.

In the space of an hour, most of Ms. Alison's class developed a rudimentary understanding of the word conflict, as it applied to the individual level. The lesson took place during the last hour of a school day, and an hour is a long time for young people to concentrate on one topic. Thus students' relative silence regarding larger-scale conflicts may have resulted from not understanding the connection, or simply from getting tired. Clearly, the conceptual connection between extended intergroup conflicts (such as Native North Americans versus European-origin Pioneers over land) and short-term interpersonal conflicts (such as disagreements with a parent over breakfast) was not immediately or fully clear to everybody in this class. Conflict as a concept was relatively unfamiliar, as this curriculum began.

To reinforce the applicability of the conflict concept to social as well as interpersonal disagreements, a homework assignment and subsequent lessons invited the class to investigate diverse opinions associated with the 'Days of Action,' a series of local work stoppages protesting provincial government policies (in relation to funding for social services and education) that were affecting many students' families at the time. Students wrote in their own journals about who was involved, what opinions various actors held, and how the media portrayed the sources and symptoms of the Days of Action conflicts. Most students showed that they were beginning to sort out the idea that there can be different viewpoints regarding the 'same' event or problem.

\section{Sources of conflict: human needs and perspectives:}

An extended series of lessons guided students to describe a variety of basic human needs, to distinguish needs from wants, and to analyze the ways unmet needs might be sources of conflict. For example on October 28, the children brainstormed and then developed drama skits in assigned (heterogeneous) small groups, depicting conflicts over meeting people's needs. Students chose and presented the following skits:

(1) There was not enough clean drinking water for everybody.

(2) There was a traffic accident because a driver (with no education) couldn't read a stop sign.

(3) One family was homeless because they had no money for rent, while another family

had a comfortable space.

(4) Two people had food, two others were hungry, and one decided to share. 
(5) A person received good medical care for a broken leg, but another student played the role of the Premier, saying he was cutting the hospital's funding.

(6) Three friends disagreed about whether to give away a coat to a person who had insufficient clothing and was cold.

(7) The air was so polluted that the actors coughed and gagged: they couldn't figure out who was to blame for this problem.

It was clear from the students' presentations that social and political conflicts were indeed part of their repertoire of experiences and concerns. Earlier class discussions about the Days of Action protests were evident in some groups' ideas. After each group presented, their classmates guessed (accurately) which needs and conflicts were involved. They had come to understand that the term 'conflict' applies to both intergroup or political and interpersonal problems.

In the brainstorming session preceding this small group work, I had prompted for less visible human needs (such as respect or affection) that would be familiar in interpersonal relationships. However, the examples students chose to develop were not interpersonal: they were social and even controversial issues. In subsequent lessons, students drew pictures reflecting conflicts over unmet human needs: again they all chose social conflicts regarding pollution and resource distribution, rather than small-scale personal conflicts. Physiological needs, and the conflicts that arise from those needs not being equitably met in our society, were tangible and meaningful to these children. Questions of psychological needs in interpersonal conflicts were either too complex or too emotionally risky to discuss here, so the students chose not to pursue them at this point. The models the students did present, and the discussions that followed, provided insights into conflict that might have been missed in a curriculum that avoided complex or politically-charged issues. This insight is significant for other areas in social education beyond conflict resolution: local, family, and home concerns are not necessarily simpler or more accessible to diverse young students than broader social concerns that have clear tangible elements (such as land, water, food, weather events, or dramatic human actions).

Ms. Alison's curriculum pursued these social and global connections in the following month, extending students' understandings of the sources of conflict and developing the idea that conflict involves different viewpoints or perspectives.

On November 6, Ms. Alison showed each student a dramatic photograph, cut from a recent newspaper, showing two hungry children reaching out for food in a refugee encampment in Zaire. She asked, "What do the people in the picture really need?" She guided the class to interpret visual clues and to distinguish the main need - food - from various "wants." Then, "Who are all the different people involved in this problem, even though they're not necessarily shown in the picture?" Ms. Alison prompted the class to imagine who was "behind" the picture, in particular the aid worker toward whom the children were reaching. "What is the problem?" Reading the caption, a student answered, "There are not enough protein biscuits to go around, and they're hungry."

Ms. Alison directed the class to act out what she called a 'tableau.' First (to all of the students, standing spread around the room), "You're the aid worker. Go around distributing food, distributing food, then you run out. Freeze. How do you feel?" Second (again to everyone), "You're a hungry person, lined up for food, waiting, the food's coming around, then they run out. Freeze. Show how you feel." In de-briefing the exercise, students put their wide-ranging responses to the conflict into words, including embarrassment, fear, frustration, envy, misery, and resignation.

Here, the class worked together to describe a human conflict of crisis proportions, and to articulate the ways various participants in that conflict might have thought and felt about the 
problem. Most members of the class showed by their serious dramatic poses, and by the vocabulary they used afterwards, that they could imagine themselves into the perspectives of participants in this conflict. This is not to say, of course, that either the teachers or the students really understood the many perspectives or complex sources of this whole conflict, as it would have looked on-site to participants in Rwanda or Zaire. In fact, it was the unfamiliarity and distance of this particular situation that made the broad outlines of this refugee food problem seem clearer. The news photograph presented only a snippet of a complex situation, and therefore presented an opportunity to highlight two key ideas in understanding (interpersonal and social) conflict - the notion of human needs, and differing viewpoints regarding what to do about those needs.

The class pursued the question of human needs and wants as a source of conflict, and the question of incompatible perspectives as an element that defines conflict, in various ways over the next month. For example, the class learned vocabulary such as refuge and refugee in relation to a school Remembrance Day program, and continued to read about and discuss the situation in Rwanda, Burundi, and Zaire as it emerged in the daily news. Several of the children's families had come to Canada for refuge from difficult situations in their own countries of origin, so these lessons served to label and clarify concepts with which some students were already familiar. Rather than raising troubling controversy (as it could have), the relevance of this curriculum to some students" "real" experiences appeared to give several quieter and newly-arrived immigrant students a reason to speak up, and their confident/settled peers a reason to listen to what they knew. By the end of November, virtually every student could describe a conflict (depicted in a picture, poem, or story), discuss who was directly or indirectly involved in that problem, and figure out what thoughts and feelings might be associated with each party's viewpoint.

This is an example of the kind of curriculum Jerome Bruner has advocated: one that helps children to interpret an essential idea that, "when fully developed, ... is worth an adult's knowing, and ... having known it as a child makes a person a better adult" (1960, p.52). Instead of assuming that the global and political dimensions of conflict over human needs would be inaccessible to these young children, Ms. Alison's curriculum translated this complex concept into dramatic and simplified forms that connected with the children's diverse life experiences and ways of thinking.

\section{Managing conflict: choices and relationships}

The next challenge in Ms. Alison's thematic unit was to extend students' understandings of conflict, applying the concept more directly to their own roles as participants in their communities. Beginning in December, a few lessons addressed the idea that participants in a conflict have choices, and that the consequences of each possible response to the conflict can be predicted and evaluated.

The Rwandan troubles again presented an opportunity to step outside of the complicated here-and-now. Ms. Alison brought in an article by Anne McIlroy in the Globe and Mail: "Hutus returning home to find Tutsi squatters," and read it in class with the students on December 2. The journalist personalizes the problem of competing claims on a homeland, by telling the story of a Hutu family of eleven who managed to get back from the refugee encampment to which they had fled during the violent outburst between Tutsis and Hutus, only to find a Tutsi family living in 'their' two room house. They ended up sharing the house, with the Tutsi family in one room and the Hutu family in the other. The journalist writes, "last night, a rock came through the window." It was not clear from whom the assault had come. The class began to define the problem, and to discuss the different ways that the people involved might handle the situation.

The next day, the class was arranged in two lines facing one another (one line acting as Tutsis, the other side as Hutus). With the children's eyes closed, Ms. Alison reviewed 
the story, ending at the moment the rock came through the window. She reminded the children to stay in place in the line, while everybody acted this out at once: "Imagine that you ran outside your room to see what was the matter, and found yourself face to face with your Tutsi (or Hutu) neighbor - the person standing across from you. When you open your eyes, tell or show your neighbor what you want, and what you are going to do. When you hear the rattle, freeze." The class acted out, observed, named, and discussed the various responses to conflict that emerged. We led the class to look for patterns in the types of choices represented - avoid [postpone or run away], fight [use violence], or try to resolve.

The homework was a language arts 'benchmark' assessment task, writing in role. Students each wrote from the point of view of the Hutu or Tutsi person they had represented in the role play. Their assignment was to describe the best solution to this conflict from the Hutu's or Tutsi's (imagined) point of view, and to explain why by predicting the consequences of that choice. Later, the class shared and summarized the many responses to this conflict that various students had imagined:

- Rivalry forever - keep fighting - might have another war

- Some people make peace

- Escape/ run away/ hide

- Ask what happened: who threw the rock?

- Help the other family to build another house

- Divide the rooms and the food, share the land

- Attack back (die or be trapped), destroy the house

- Say this is 'my' house, make the other group get out

- Negotiate - we will leave if you help us build more houses

- Get somebody to give us another bed and room

- Call for help - are there police?

- Vote on two presidents for the country - one Tutsi, one Hutu

- Split the country in half

First, the class reviewed the distinction between avoidance, using violence, and confronting the conflict, and students categorized the above responses accordingly. Next, students predicted the consequences of each response, and labeled them Win-Win, WinLose, or Lose-Lose.

The dichotomous categories of "win" and "lose" are simplified schema used often in conflict resolution education, even though of course they do not map perfectly onto these real human scenarios. Students agreed unanimously that some of the responses to this conflict were Lose-Lose or Win-Lose choices. On other responses, however, students disagreed about the consequences they predicted: some students' views were more pessimistic than their classmates.' I could identify no clear pattern regarding which students had which views -- recent and longsettled immigrants, and boys and girls, were distributed quite evenly among the optimists and pessimists. Their fervent discussions about these predictions served as a think-aloud exercise, in which children modeled for one another how various actors might respond to various conflicts, and how to predict and evaluate the results of such actions. This conceptual framework was applied, in subsequent lessons, to conflicts in various children's stories.

Managing conflict extended: choices and relationships in bullying

In January and early February, Ms. Alison directed the class's attention to a kind of

conflict that occurred much closer to home. Through art, language, literature, and social studies lessons, the class applied their new vocabulary regarding conflict to the problems of teasing, 
bullying, and exclusion, emphasizing the ways these problems occurred on and around their own school playground. The key ideas studied earlier - human needs, different perspectives, choices and consequences in handling conflict - were now applied at a more complex (though local) level.

Bullying/ exclusion problems are challenging instances of conflict for young students like Ms. Alison's class, for various reasons. First, bullying and exclusion are complex conflicts because they involve unequal power, and shifting relations of power as groups re-form and target various individuals. Second, these problems were complex for these students because many of them were direct or indirect participants - the conflicts involved themselves or people they knew, about whom they had complicated feelings. Third, bullying conflicts are qualitatively different from the conflicts discussed earlier, because the human needs at their root involve intrapersonal conflicts over intangibles such as self-respect and friendship, rather than involving clear disagreements regarding how to handle a visible problem. Thus this locally-familiar problem was a more difficult application of the concept of conflict.

Most of the children were by now eager to talk about these problems. The foregoing months of concept-building provided a crucial foundation for their discussions.

On January 7, Ms. Alison invited students (in small mixed groups) to imagine and draw pictures of bullies. Later, she asked students to add words: "What would the bully be saying?" Debriefing with the whole class, Ms. Alison asked, "How would you describe these bullies?" Students described a single big, strong, rude, male. Some students also described individuals who were 'dumb,' wore torn clothing, and spoke slang.

Ms. Alison asked, "Who usually gets picked on?" Students listed smaller people, younger children, disabled people, and people who seem different from the norm. When the teacher asked, "Who has ever felt like they wanted to bully somebody?" about twenty students raised their hands (many of them tentatively, waiting to see what peers did, first). "Why?" Ms. Alison asked. Children mentioned having been hurt themselves, either by the same person or by somebody else.

The similarity of the students' initial images of bullies to prevailing cultural stereotypes suggests that these conceptions are not necessarily well-rooted in the children's own experiences. Some children's images carried unconscious social class bias - emphasizing characteristics such as worn out clothing, colloquial speech patterns, rude manners, or failure in school. This notion of the bully is common in some children's literature; thus students may have been opening the conversation with the 'school knowledge' they imagined the teacher wanted to hear.

As the students became more comfortable discussing the issue, and more skilled in applying new vocabulary to their own experiences, a different image of bullying emerged. Later class discussions, as well as the research literature on bullying, generally describe groups of children (of either gender) picking on or excluding another child, rather than single 'bad boy' individuals terrorizing weaker peers (Pepler \& Craig 1994). Just as students had initially understood 'conflict' simplistically as fighting or violence, students initially understood the term 'bullying' as referring to individual 'bullies.' This simpler conception may have allowed the children to externalize the problem (blaming it on 'bad people'), but even so almost two-thirds of the class was willing to admit that they had felt the inclination to bully others.

To begin a lesson the following week (January 14), I read aloud another children's book: Name Calling, by Itah Sadu. As usual, I stopped frequently to invite students to interpret various characters' feelings, to predict consequences of various actions, and so forth. The new element in the curriculum, raised by this story, was the idea that the conflict 'escalates, 'in this case by compounding the misunderstanding and adding more children to the group that was picking on a schoolmate. The class discussed the phenomena of groups picking on individuals and of conflict escalation, comparing these 
with their earlier conceptions of bullying.

Next, Ms. Alison brought out an essay from a recent newspaper, called "Four-season games for girls." She read aloud, "The high school football season is coming to an end, but the games that girls play go on for all seasons. 'Target' is a favorite sport of adolescent girls. It requires no skill, no strength and no brains. The strategy is to single out one particular girl to humiliate and isolate" (Bonenfant 1997, p. A16). Ms. Alison noted that the article was about older girls, but that she thought it also would sound familiar to this group. She asked, "What kind of games might this be?" After a couple of minutes of thinking aloud, students made the connection to the book they had just read: "target" referred to picking on people, bullying.

"Why would we say that calling people names is like a game?" Ms. Alison asked. Several students volunteered immediately that picking on somebody could be fun, and that when bullying with a group, "You're like, protected.... You feel strong." Other students noticed that bullying, like many games and some conflicts, involves winning and losing. "Who has been picked on, a target?" At least 25 of the 32 children present raised their hands. "Who has been part of a group that picked on somebody?" Fourteen raised their hands. The discussion continued, probing the feelings of various children when they ganged up on somebody or were picked on. In asking students to predict the consequences of such bullying or targeting, the teacher reinforced the concept of conflict escalation.

It is evident that nearly all of the students were beginning to demystify the concept of bullying, connecting it to their own experience. Most were apparently able to identify (to varying degrees) with 'bully' as well as 'target' experiences. The following week, students in small groups wrote and acted out bullying skits, showing (by their inclusion of feelings and reasons for the problem) that they understood bullying situations to be a type of conflict. Their scenarios included: stealing a target's lunch money, calling a target a nerd for reading during recess, forcing a target to do others' homework, and exacting revenge for a target having bullied someone's little brother. Most groups demonstrated escalation in their skits, without having been prompted. The class discussed the problem that conflicts involving several people, once they had escalated, were very difficult to resolve. Over the next few weeks, most students thoughtfully considered the complex nature of bullying, and their own roles as potential or real participants in these kinds of conflicts.

In a second writing-in-role assignment, Ms. Alison gave the class a general scaffold for including all of the characters and different viewpoints in a story about bullying. All but two (of 30 handed in) showed that they could write fairly coherently about a complex conflict from the point of view of one of its participants. Almost equal numbers of students chose to write from the role of bullies (13, including 9 boys) as of targets (15, about equally boys and girls). (Two did not clearly write in role.) Of those who wrote in the 'bully' role, most (10) described themselves as followers, rather than ringleaders, of bullying activities. I have selected two sample stories written in the role of targets, followed by two in the role of bullies. I chose these examples to show the group's range of feelings, typical explanations for bullying and typical ways they handled the problem. (Children were instructed to make up pseudonyms; I reproduce the children's original spelling, some of which they corrected in later revisions. The stories with all female characters were written by girls; those with male or mixed characters were by boys.)

- Sarah has been targetted by Victoria, Linda, and Judy, because Sarah is a Chinies and Victoria, Linda, and Judy are English. Sarah dose not know how to speak English because she is Chinies. She also has black hair and looks different. Victoria, Linda and Judy calls names, like there is baddy. Victoria is the leader. I am Sarah. Sarah is always 
been picked on.... She feels very sad and lonly and having no protection.

- Monttey has been targetted by Kam, San, and Mickey because he has dark skin, glasses and he can't speak english well. Every day Kam, San, and Mickey want 25 cents from Monttey. Also they beat him up. Sometimes at school they blame stuff on him. I am Monttey. He doesn't like what there doing to him at all. Every day he get's scared and sometimes he doesn't even come to school. Every day he cries and gets mad but he doesn't tell teachers.

-Wendy has been targetted by me, Cable and Dinar, because we saw my sister getting beat up by Wendy. I'm the leader. Me, Cable, Dinar beat her up and We felt tough. We said to our selfes that it felt good beating her up. But I was worried she was going to get her gang but she told the teacher and we got in trouble.

- Lida has been targetted by Angie, May and Tina, because it took Lida 20 minutes for her to answer a math question. Angie is the leader. I am May. At first it felt good to pick on someone, but then I reallized that Lida hadn't done anything to hurt me or my feelings and then I remembered I wasn't so good in today's math sesion either.... In a way me and Lida are exacley alike. We dressed alike, we think alike, we're both horrible at math and we both loved to read. If Angie and Tina hated Lida so much why didn't they pick on me?

It is no surprise that children cited perceived difference (including immigrant status, racial characteristics, and level of academic success) as a major reason for bullying conflicts (one story involved a student being targetted for being a 'nerd,' while several targetted a student with academic difficulties). Many bullies enjoyed feelings of strength and power, at least temporarily, while some felt confusion, remorse, empathy for the target, or fear of retaliation or punishment.

Most of these young students, in this and further lessons through January and early February, showed that they had come to understand many of the subtleties (not just the symptoms) of conflict and conflict management. By applying the concept of conflict (developed earlier in relation to complex but distant social problems) to the personal phenomenon of bullying in their own schoolyard, students deepened their understandings of the major elements of conflict, including: point of view or perspective, the uneven relationship of feelings to actions, the idea that participants in conflicts have choices and the idea that their actions have consequences for self and others.

\section{Managing conflict further extended: conflicts over resources and land}

In the term beginning in February, the conflict theme was extended to embrace math, science, and technology in addition to social studies and language, particularly through the study of water cycles, waterways, and human uses of water. A series of lessons and projects in March and April reviewed and extended students' understandings of human needs, wants, and conflict by focusing on global and local disagreements over the uses of water resources. In May and June, the class embarked on an area study of the Middle East. They identified conflicts over water scarcity, control of land and oil resources, and poverty, as well as ideological and religious differences, as focal points for the study of that region. In pairs or threes, students examined particular Middle Eastern countries, and contributed to a wall chart comparing geographic, demographic, and cultural data from the various countries.

In June, the whole class sat in a circle to discuss their deductions and interesting findings regarding the people of the Middle East. Students showed their understandings of conflict in comments such as the following, regarding government spending priorities.

- If a country, such as Saudi Arabia, made a lot of money from selling oil, then why is the 
health care so bad [referring to high infant mortality rate of 59 per 1000]?

- If a country has a lot of oil, the government could pay for good services like health care and schools. Some countries do this more than others.

As often happened in this class, initial participation in this complex thinking-aloud process was fairly small, involving mostly five or six students, but as children got more comfortable with (and thus interested in) the ideas, involvement rose to include about twice that many active voices. About half the class was attentive but noticeably quiet, even when encouraged or cajoled to participate.

Summing up: What is conflict and what are its major elements?

June 19 was the last research visit, taking place only a few days before the end of school. The activity was set up to see how the students might answer the same question addressed at the beginning of the project: What is conflict?

Ms. Alison asked the students to once again assemble in (assigned heterogeneous) small groups, and to show what they understood about conflict by dramatizing a "real-life" conflict, either one that had happened to somebody in their group or one they had read about. Each presentation included a narrator, who described the setting and introduced each character. After each group performed their skit, the rest of the class worked together to identify the cause of the conflict in the skit ("what is the problem?"), the various viewpoints ("Who is involved and what do they want?"), and the form taken by the conflict ("what happens?""Was there escalation or violence?"). Last, each small group improvised and then evaluated possible solutions to each conflict (win-win, win-lose, or lose-lose and whether the solution seemed feasible and sustainable).

- One group acted out a bullying situation, in which one child was picked on by schoolmates and blamed for something he hadn't done. Classmates identified the different viewpoints of the various characters, labeled their feelings, and described the escalation of the problem. The group invented several solutions that involved gathering further information, negotiating, and getting help.

- The second group presented a sibling conflict, in which a child was frustrated about his younger brother's continual interruptions and disturbances. Classmates again correctly interpreted the characters' viewpoints and escalating anger. They worked out a complex integrative solution, in which parents agreed to entertain the little brother for a short time, while the older brother found a quieter place to sit and agreed to play with his little brother later.

- The third group presented a skit in which several boys were teasing a girl who couldn't kick the ball very far during a recess kickball game, while other characters stood by and did not intervene. The class identified the sense of male superiority experienced by those doing the teasing, the hurt, embarrassment, and empathy experienced by the bystanders, and the misery of the target. The girls, in particular, talked about the ways that they, too, felt targetted, because they felt that many girls were teased frequently. Their solution was to band together, get another ball to use in a different part of the schoolyard, and coach one another to improve their strength and ball-handling skills in a less-competitive atmosphere.

- The last group presented a complex conflict over resources, specifically "who gets the land," in Israel/ Palestine. The skit included a lot of dialogue that escalated into name calling, stone throwing, and rubber bullets. The children playing Israeli Jews described 
their worries about security in what they saw as their homeland; the children playing Palestinians described their sense of loss, outrage, and insecurity about not controlling what they saw as their homeland. The class recommended peace talks, negotiating a fair division of the land, and building houses somewhere else rather than on disputed land.

To sum up, Ms. Alison and I led the class to compare the ways each of these and other scenarios exemplified different types of conflict, and the ways each conflict had various causes, contrasting viewpoints, choices and needs involved, and possibilities for solution.

The students' work showed phenomenal variety and depth of understanding. I cannot verify from this scant evidence that every child understood every element of conflict, nor that the understanding they did develop improved their long-term success in social education or in democratic citizenship. However, the year's activities and the final presentations demonstrated that most of this class of 9 and 10 year old children had developed a remarkable familiarity with and capacity to use some major concepts and generalizations associated with conflict, conflict resolution, alternatives to violence, and the social contexts that give rise to particular kinds of conflicts. Every child in the class was involved in presenting a conflict scenario, and every one made a few coherent comments about each of the other conflict scenarios presented. This shows that they had some understanding of the causes and forms of conflict, the role of conflict in human relationships, the ways conflicts may present choices, and the range of possible conflict resolution processes.

\section{A partial conclusion:}

This research connects two major components of democratic social education-social relationships in a particular learning climate, and inclusion of conflict in the content of academic lessons. The relationships among the diverse members of this class, and thus their opportunities to safely practice managing conflict, were facilitated by multiple communication strategies such as artwork, drama, writing, and respectful small or large group discussions. The academic world was unlocked, and fused to students' lives and interests, through concentrated attention to the concept of conflict. This powerful and motivating theme provided meaningful applications for core curricular ideas and skills, especially in language arts and the social studies.

Ms. Alison's students benefitted from the inclusion of far-away and large-scale, as well as local and interpersonal, problems as learning opportunities. The non-linear approach to the social studies concept of conflict, including the early and frequent inclusion of politically controversial or complex international material, seemed to enhance these children's learning experience by providing multiple representations and many entry points for understanding main ideas. Each child handled the ideas raised in class at their own developmental level, drawing upon their own diverse experiences to make sense of what was unfamiliar. Conflict is pervasive in social life, so conflict appeared in a very wide range of their interpersonal and academic endeavors during the months this curriculum unit was conducted. This global and local conflict education helped them to connect their multiple worlds to the fabric of school knowledge (Phelan et. al. 1991). Thus the time spent on conflict management enhanced, rather than replacing, their academic learning. Conflict learning was indeed woven together with social studies and language achievement.

The most important contribution of such an exploratory study is to highlight questions for future discussion and research. The most troubling question highlighted by this research is by no means new. This is the problem of inclusivity and success for all (e.g. Bergsgaard 1997, Bettman \& Moore 1994, Bickmore 1996, Means et. al. 1991). In most of the lessons I witnessed in Ms. Alison's class, it was clear that the children all found conflict study to be intrinsically interesting. Many, but not all, of the children who were unaccustomed to being deeply or confidently involved in their public school education (that is, who were withdrawn in Ms. Alison's other lessons) were drawn in by the content and pedagogical processes associated with conflict-embracing education. The children seemed to develop their confidence and understanding through the active processes of thinking aloud, 
discussing, and acting out a wide range of conflicts. The question is, what was learned by the quieter and more passive students in this class? If inclusive conflict education is essential to the development of democratic citizenship and civic culture, then even Ms. Alison's brilliant class illustrates the pitfalls and partiality where such learning is not completely inclusive. The content regarding conflict, and the pedagogical emphasis on drama and discussion, did show some hopeful signs of beginning to address this challenge, but it did not completely solve the problem of inclusivity in the learning process.

A limitation of this study is that it is based on only one case, in a relatively unusual elementary classroom. It demonstrates possibility, not typicality. Ms. Alison's extensive wisdom of experience, and the presence of an extra adult to think and plan with, made it possible for her to overcome obstacles to innovation that might have been much more difficult for another teacher. In particular, Ms. Alison had remarkable skills in using drama and the arts to strengthen academic curriculum and to make it more accessible to students with limited English proficiency. Equally important, this school's and school board's emphasis on conceptually rich thematic curriculum, rather than on a more linear approach emphasizing history or geography information, gave Ms. Alison the space to focus on the conflict as a social concept for several months of a school year. The existence of a small but significant problem with bullying and fighting in this school's playground provided a rationale for making time to address conflict and conflict resolution. This large class of 33 students at two grade levels, many of them recently arrived from different parts of the world, was a challenging context that paradoxically made more traditional approaches to social education unlikely to succeed, and thus strengthened the rationale for trying something different. This observational study was not designed to substantiate the success of this curriculum in terms of individual students' learning outcomes, but it does show these diverse students engaging in learning opportunities in ways that should encourage future experimentation and research in this area.

This study presents a challenge to some conventional approaches to both elementary school conflict resolution and social studies education, by refuting the 'expanding horizons' assumptions upon which much of it is often based. Generalizations and comprehension of concepts tend to be sounder when they are based on a wider range of contrasting examples (Taba 1969). Thus, when young people study community and global (as well as interpersonal) conflicts, their eventual understanding of conflict is thereby refined and clarified. The contrasting examples in this extended unit on conflict resolution provided points of entry for the insights of children with diverse life experiences, thus enriching the learning resources available to the whole classroom group. The powerful themes of social, political, and interpersonal conflict enhanced the breadth and depth of these young students' involvement in social education. Yes, children can handle global politics, and doing so can help to increase their capacity to handle both interpersonal conflict and academic skills. 


\section{References}

Anzaldúa, G. (1987). Borderlands/ La Frontera: The New Mestiza. San Francisco: Spinsters/ Aunt Lute.

Bergsgaard, M. (1997). Gender issues in the implementation and evaluation of a violence-prevention curriculum. Canadian Journal of Education 22:1 (Fall), 33-45.

Bettman, E. \& Moore, P. (1994). Conflict resolution programs and social justice. Education and Urban Society vol. 27 no.1 (November), 11-21.

Bickmore, K. (1996). Women in the world, women in the classroom: gender equity in the social studies. High School Journal vol. 79 no.3 (February), 231-241.

Bickmore, K. (1997). Preparation for pluralism: curricular and extra-curricular practice with conflict resolution. Theory Into Practice vol. 36 no. 1 (Winter), 3-10.

Bickmore, K. (forthcoming 1999). Teaching Conflict and Conflict Resolution in School: (Extra-) Curricular Considerations. In A. Raviv et. al. (Eds.), Children's and Adolescents' Understandings of War, Conflict and Peace (SF: Jossey-Bass).

Bonenfant, C. [Claire] (1997), "Four-season games for girls." The Globe and Mail (January 6), p.A14.

Carruthers, W., Carruthers, B., Day-Vines, N., Bostick, D., \& Watson, D. (1996). Conflict resolution as curriculum: a definition, description, and process for integration in core curricula. The School Counselor 43: 5 (May), 345-373.

Curle, A. \& Dugan, Maire (1982). Peacemaking: stages and sequence. Peace and Change vol. 8 no. 2/3 (Summer), 19-28.

Deutsch, M. (1993). Educating for a peaceful world. American Psychologist vol. 48 no. 5 (May), 510-517.

Egan, K. (1988), Teaching as Storytelling. London: Routledge.

Elkind, D. (1995). School and family in the postmodern world. Phi Delta Kappan vol. 77 no. 1 (September), 8-14.

Glaser, B. \& Strauss, A. (1967). The Discovery of Grounded Theory: Strategies for Qualitative Research. NY: Aldine de Gruyter).

Hahn, C. (1996). Empirical Research on Issues-Centered Social Studies. In R. Evans \& D. Saxe (Eds.), Handbook on Issues-Centered Social Studies. Washington, DC: National Council for the Social Studies (Bulletin \#93), 25-41.

Houser, N. (1996). Negotiating dissonance and safety for the common good: social education in the elementary classroom. Theory and Research in Social Education vol. 24 no.3 (Summer), 294-312.

Johnson, D. \& Johnson, R. (1996). Conflict resolution and peer mediation programs in elementary and secondary schools: a review of the research. Review of Educational Research vol. 66 no. 4 (Winter), 459-506.

Keller, E. (1985). Reflections on Gender and Science. New Haven: Yale University Press.

Kreidler, W. (1990). Elementary perspectives: teaching concepts of peace and conflict. Cambridge, MA: Educators for Social Responsibility, 229-236.

Kriesberg, L. (1982). Social conflict theories and conflict resolution. Peace and Change vol. 8 no. 2/3 (Summer), 3-17.

Means, B. Chelemer, C. \& Knapp, M. (1991), Teaching advanced skills to at-risk students. San Francisco: JosseyBass.

Mellor, S. (1996). The Centrality of an active, experiential pedagogy to learning outcomes in citizenship education. Presented at Culture and Citizenship Conference (Brisbane) <http://www.gu.edu.au/ gwis/akccmp/papers/Mellor.html> (December).

Merelman, R.(1990). The Role of conflict in children's political learning. In O. Ichilov (Ed), Political Socialization, Citizenship Education, and Democracy. New York: Teachers College Press, 47-65.

Merryfield, M. \& Remy, R. (1995). Teaching about international conflict and peace. Albany: State University of New York Press.

Miner, B. (1998). Reading, writing, and censorship: when good books can get schools in trouble. Rethinking Schools 12:3 (Spring), 4-6.

Noguera, P. (1995), Preventing and producing violence: a critical analysis of responses to school violence. Harvard Educational Review 65:2 (Summer), 189-212.

Opffer, E. (1997). Toward cultural transformation: comprehensive approaches to conflict resolution. Theory Into Practice vol. 36 no.1 (Winter), 46-52.

Pepler, D. \& Craig, W. (1994). About bullying: understanding this underground activity. Orbit 25:3, 32-34.

Phelan, P, Davidson, A.L, \& Cao, H.T. (1991), "Students' multiple worlds: negotiating the boundaries of family, peer, \& school cultures." Anthropology and Education Quarterly 22:3, 224-250. 
Sadu, I. Name Calling.

Scheurman, G. \& Newman, F. (1998). Authentic intellectual work in social studies: putting performance before pedagogy. Social Education 62:1(January), 23-25.

Soley, M. (1996), If it's controversial, why teach it? Social Education vol. 60 no. 1 (January), 9-14.

Taba, H. (1969). Teaching strategy and learning. In Herman, W. (Ed.), Current Research in Elementary School Social Studies. NY: Macmillan, 103-117. 